\title{
Alfred Métraux y la utopía del Gran Chaco
}

Alfred Métraux et l'utopie du Gran Chaco

Alfred Métraux and the Gran Chaco utopia

\section{Federico Bossert}

\section{OpenEdition}

\section{Journals}

Edición electrónica

URL: https://journals.openedition.org/jsa/14826

DOI: $10.4000 /$ jsa. 14826

ISSN: $1957-7842$

\section{Editor}

Société des américanistes

\section{Edición impresa}

Fecha de publicación: 31 diciembre 2016

ISSN: 0037-9174

\section{Referencia electrónica}

Federico Bossert, «Alfred Métraux y la utopía del Gran Chaco», Journal de la Société des américanistes [En línea], 102-2 | 2016, Publicado el 17 enero 2017, consultado el 04 septiembre 2022. URL: http:// journals.openedition.org/jsa/14826 ; DOI: https://doi.org/10.4000/jsa.14826

Este documento fue generado automáticamente el 4 septiembre 2022.

All rights reserved 


\title{
Alfred Métraux y la utopía del Gran Chaco
}

\author{
Alfred Métraux et l'utopie du Gran Chaco \\ Alfred Métraux and the Gran Chaco utopia
}

Federico Bossert

\section{NOTA DEL EDITOR}

Manuscrit reçu en janvier 2016, accepté pour publication en juin 2016.

1 El Gran Chaco fue la región a la que el joven Alfred Métraux dedicó sus primeros esfuerzos etnográficos. El objeto de estas páginas no es analizar sus muchos y dispares escritos sobre esta zona, sino más bien reseñar el contexto biográfico de esas investigaciones, desarrolladas principalmente entre 1929 y 1934 - cuando ocupó el cargo de director del Instituto de Etnología de Tucumán - y en 1939, cuando regresó a la región financiado por la fundación Guggenheim. Este análisis, centrado más en la correspondencia de Métraux que en su producción académica, nos permitirá apreciar el lugar central que el Chaco ocupó en su variadísima y siempre cambiante agenda etnográfica, y la notable persistencia, a lo largo de toda su vida, del proyecto de investigación sobre esta región que fijara al comienzo de su carrera. Para dilucidar las razones - académicas y personales - de esta importancia y persistencia, prestaremos especial atención a la influencia que tuvo sobre la formación y los planes científicos de Métraux quien fuera su gran maestro en las artes etnográficas: el etnólogo sueco Erland Nordenskiöld ${ }^{1}$.

\section{Años de formación}

2 Antes de preguntarnos cómo llegaría Métraux a interesarse tan intensa y prolongadamente por el Gran Chaco, debemos mencionar, a manera de prólogo 
anticuario, su primera, fugaz, y seguramente accidental experiencia chaqueña. Métraux realizó su primer viaje etnográfico en 1922, cuando todavía era alumno de la École des Chartes. Esta investigación, en principio destinada a reunir fuentes históricas sobre la región diaguita, tuvo sin embargo un desvío hasta los lindes del Chaco del que nos llegan rastros difusos: la fugaz mención a una entrevista con un cacique wichí en el Chaco argentino, una lista de piezas donadas al Museo de Göteborg que incluye cerámicas chorote recogidas en la frontera de Argentina y Bolivia ${ }^{2}$. Como sea, es bien sabido que regresó a París con la firme intención de " convertirse en un etnólogo especializado en América del Sur» (Métraux 1963, p. 677). El Chaco, pues, estuvo allí desde el comienzo, formó parte del viaje que lo apartaría de la carrera archivística y definiría su vocación etnográfica. De hecho, su primer artículo importante, De la méthode dans les recherches ethnographiques (1925), recurría a sus primeras - y frustrantes - experiencias chaqueñas para ilustrar las dificultades que el investigador encuentra en el terreno ${ }^{3}$.

3 En Francia, por aquellos años, el más prominente etnólogo americanista era Paul Rivet, quien debe ser considerado el factótum de la vida académica temprana de Métraux. En primer lugar, fue bajo sus augurios que Métraux realizó el viaje de estudios a Göteborg que daría una dirección mucho más concreta a esa flamante vocación etnológica (AM a EN, París, 05/07/1925, VM). Curiosamente, no fue él sino su prometida, Eva Spiro, quien llegó primero a Suecia recomendada por Rivet para realizar estudios en etnografía americana junto a Nordenskiöld (PR a EN, París, 14/01/1925, VM; EN a PR, Göteborg, 19/01/1925, MNHN, Ms. 1/6699). Métraux todavía cursaba sus estudios de licenciatura en París, y recién iba a seguirla algunos meses más tarde. En su primera carta a Nordenskiöld - en julio de 1925 - Métraux se disculpaba porque Eva finalmente no había llegado a Göteborg, y anunciaba que él mismo planeaba viajar allí por algunos meses para asistir a los cursos de etnología: « considero un deber hacia mí mismo » - escribía con solemnidad juvenil - « no comenzar mi carrera como americanista sin haberme expuesto a su influencia de un modo directo » (AM a EN, París, 25/06/1925, VM). La respuesta del sueco debió ser alentadora, porque en la siguiente carta Métraux prolongaba su estadía: al menos un año y medio; de ese modo, decía, no sólo asistiría a los cursos sino que también prepararía « un trabajo importante bajo su dirección » (AM a EN, París, 05/07/1925). Ese trabajo iba a ser su tesis doctoral sobre la cultura material tupí-guaraní. Hay que señalar que Métraux decidió asistir a los cursos de Nordenskiöld por más que, en aquel entonces, sus conocimientos del sueco eran poco menos que rudimentarios. Algo tenía de iniciático, de rito de paso, ese viaje de estudios: «Parto », escribía, « con la esperanza de ganar su confianza y regresar de Suecia bien armado para la carrera de etnógrafo que he elegido » (AM a EN, París, 05/07/1925, VM).

4 Al parecer, Métraux llegó a Göteborg a fines de agosto de 1925. E inmediatamente comenzó un trabajo de investigación: cuando Marcel Mauss visitó el museo, apenas dos meses más tarde, lo encontró ya concentrado en "su tesis " ${ }^{4}$. Todo indica que su interés inicial por la civilización tupí-guaraní nació en Göteborg, y fue inculcado por Nordenskiöld. De hecho, su famoso hallazgo de manuscritos de Thevet en la Biblioteca Nacional de París - hito central en su investigación paralela sobre la religión tupinambá (Métraux 1928b) - es posterior a su estadía en Suecia ${ }^{5}$. Así pues, durante casi dos años, hasta mediados de 1927, el joven Métraux estudió y trabajó de modo más o menos permanente en Göteborg. En el archivo del viejo Museo Etnográfico de esa ciudad encontramos algunos rastros de sus actividades cotidianas: redactaba cartas en francés para su maestro y gestionaba la publicación de uno de sus libros en París. La 
correspondencia entre ambos se reanudaría en agosto de 1927, y esas cartas de Métraux serían enviadas desde el Instituto de Etnología. Entre sus principales actividades de esta época se cuentan su defensa doctoral en junio de 1928, la edición de sus dos tesis (1928a y 1928b), la colaboración con la gran exposición de «artes antiguas de América » en el Museo de Arte Decorativo (Laurière 2008, p. 276); luego vendrían viajes por Inglaterra, Alemania y Austria para visitar museos y antropólogos, y una última visita a Göteborg antes de partir hacia Tucumán como director del flamante Instituto de Etnología de esa ciudad.

5 Ya a mediados de 1927, Métraux escribía a Nordenskiöld que Rivet le había prometido buscarle un puesto en Sudamérica: « ¡Mi mayor deseo es poder hacer un viaje entre los indios, y no ser sólo un etnógrafo de biblioteca! Los viajes son la mejor parte de nuestra ciencia » (AM a EN, Clarens, 22/08/1927, VM). La carta de recomendación que Rivet envió al rector de la Universidad de Tucumán anunciaba: «Métraux es mi mejor alumno y también [el] de Erland Nordensköld. Si fuera francés, yo lo hubiera guardado aquí, pero es suizo y Ud. sabe que la ley francesa no admite funcionarios extranjeros. Yo le doy una joya, y si usted la acepta, puedo decirle que Tucumán tendrá el mejor etnólogo de toda América » (Berberian y Capuano 1974, p. 10) ${ }^{6}$.

\section{Un proyecto para el Instituto de Etnología}

Métraux llegó a Tucumán a comienzos de diciembre de 1928, acompañado por su mujer y su pequeño hijo. Las primeras cartas que enviaría desde esa ciudad estaban animadas por un optimismo exaltado, y consignaban grandes ambiciones ${ }^{7}$. Había llegado con un proyecto de trabajo bien definido y a largo plazo. Desde un primer momento, tanto en su correspondencia como en el "Plan para la creación de un Museo Etnográfico en Tucumán" que presentó a la Universidad (Métraux 1929b), expresaba claramente sus intenciones etnográficas para los próximos años: en una palabra, priorizar la etnografía del Chaco. Aquí debemos recordar que la ciudad de Tucumán y la mayor parte de esa provincia se ubican en una zona de valles y serranías en las estribaciones andinas, la cual había sido habitada por culturas indígenas con fuertes influencias andinas, y cuya arqueología resultaba de suma importancia. Podemos imaginar que, bajo el mando de cualquier otro director, el Instituto de Etnología hubiera priorizado el estudio de la arqueología y el folklore local. Seguramente previendo que los intereses locales contrastarían con sus propias intenciones, Métraux acumulaba argumentos para privilegiar el estudio etnográfico del Chaco por sobre cualquier otra actividad: era importante - afirmaba - que el Museo poseyera colecciones de una región que formaba parte de la historia de Tucumán, las cuales, a diferencia de las arqueológicas, exhibirían al visitante todos los aspectos de la vida material de la tribu en lugar de piezas arqueológicas sueltas.

De hecho, Métraux ya traía en su equipaje un atado de valiosos manuscritos para la etnografía chaqueña. En Praga, justo antes de viajar a Sudamérica, había conocido a Vojtěch Frič, de quien anotó algunos mitos de los lengua y chamacoco, y de quien obtendría - por intermedio del lingüísta Čestmír Loukotka - un número de vocabularios, diarios de viaje y manuscritos inéditos de uno de los pioneros de la etnografía del Chaco, Guido Boggiani ${ }^{8}$. Traía esos papeles con la intención de publicarlos en Argentina - y, en efecto, publicaría en su propia revista el diario del segundo viaje a los caduveo (Boggiani 1930). 
Todas sus cartas y escritos de estos primeros momentos en Tucumán apuntaban al mismo ambicioso fin: el estudio exhaustivo, sistemático y urgente del Gran $\mathrm{Chaco}^{9}$. Apenas designado director, Métraux exponía esos planes a Nordenskiöld en toda su magnitud etnográfica: «Pienso arreglármelas para partir al Chaco a comienzos del año próximo, donde reuniré colecciones entre los chiriguano, los toba, los mataco y los chorote. Estudiaré asimismo la cuestión de los tsirakua y los mejores medios de llegar hasta ellos » (Lausanne, 15/08/1928, VM). En otras palabras: en su primer viaje planeaba visitar aldeas de prácticamente todos los grandes grupos del Chaco argentino y boliviano. Ya instalado en Tucumán, mientras preparaba su primera expedición a la chiriguanía, escribía una carta todavía más explícita a Lehmann-Nitsche: «prefiero guardar los fondos de los que dispongo para un gran viaje hacia el Chaco, tal vez hacia los indios toba o lengua, y en cualquier caso hacia los chorote y ashluslay. Estoy bien decidido a llevar a cabo, contra viento y marea el estudio sistemático del Chaco " (Tucumán, 06/02/1929, IAI, itálicas mías). El factor que volvía prioritario el estudio de las culturas chaqueñas era la inminencia de su transformación por contacto con el frente colonizador - que, a ojos de Métraux, equivalía poco menos que a su desaparición. Uno de sus argumentos para dedicar el museo al área chaqueña expone la idea que encontraremos repetida mil veces en sus cartas y escritos de esos años: "Los últimos grupos indios que viven sobre el territorio argentino desaparecen rápidamente y más rápidamente aún su civilización material e intelectual. Se puede calcular que en veinte o treinta años no será más posible efectuar su estudio" (1929b, p. 1). Su primer viaje etnógrafico a la chiriguanía iba a reafirmar esa convicción apocalíptica; desde allí escribía a Marcel Mauss: «La última hora para los indígenas del Chaco está por sonar, y temo que mi viaje sea el último que un coleccionista puede hacer entre ellos con algún provecho » (Cuevo, 09/03/1929, CF). De aquí en más, prácticamente cada vez que escribió sobre los indígenas del Chaco, Métraux vaticinó la desaparición de sus culturas apelando a metáforas escatológicas: " civilizaciones que mueren ", colecciones de mitos reunidas "in extremis ", tradiciones que desaparecerían junto con los últimos ancianos (Bossert y Villar 2007). Una etnografía chaqueña de salvataje, en estas circunstancias, se volvía todo un imperativo, la irrenunciable respuesta al "grito de alarma dado hace muchos años por el ilustre Bastian $»^{10}$.

9 Las ambiciones de Métraux, entonces, estaban a la altura de la promesa hecha por Rivet al rector de la universidad: en pocos años esperaba llevar a cabo la etnografía exhaustiva y sistemática del Chaco y convertir su museo en el mayor centro de estudio del mundo especializado en esa región. Sabemos que este proyecto fue recibido con entusiasmo por la élite tucumana que ocupaba los puestos directivos de la universidad. La cual, aun después de que Métraux partiera hacia la Isla de Pascua en 1934 - con la velada intención de nunca más regresar-, continuaría esperando que, tarde o temprano, retornase a « terminar su investigación sobre el Chaco $»^{11}$.

\section{Viajes al Chaco (1929-1933)}

Sin embargo, durante su estadía en Tucumán entre 1929 y 1934, Métraux consiguió realizar apenas tres expediciones a esta región: la primera a los chiriguano y chané, entre febrero y junio de 1929, la segunda a los pilagá, los toba-pilagá y los wichí entre diciembre de 1932 y abril de 1933, y la tercera a esta misma región (con un curioso desvío 
hasta Santa Cruz de la Sierra) entre agosto y diciembre de ese año. Una cuarta y última, en 1939, sería realizada desde Estados Unidos y financiada por la fundación Guggenheim.

11 Como nota al margen, debemos señalar que, más allá de estas grandes expediciones, indicios dispersos en su correspondencia prueban que Métraux también realizó otros viajes breves al Chaco, durante los cuales sin dudas llevaba a cabo estudios etnográficos. En una carta de 1929, mencionaba una visita a los nivaclé en la que registró mitos (« todo un capítulo del Popol-Vuh», dice), y acerca de la cual no encontraremos la menor referencia en sus trabajos (AM a EN, 15/10/1929, VM). En septiembre de 1932 acompañó a los escritores Drieu La Rochelle y Oliverio Girondo en un largo periplo por diversas aldeas indígenas (Krebs 2007; Amenta 2008, p. 164; AM a YO, Tucumán, 28/07/1932). Y poco tiempo después, invitaba a su amigo sueco Stig Rydén, recién llegado a Tucumán, a visitar el Chaco « por un par de días »"

De todas maneras, el proyecto chaqueño de Métraux debe ser considerado no sólo a la luz de los viajes que efectivamente consiguió realizar sino también, y tal vez ante todo, a la luz de los planes de viaje que conocemos a través de su correspondencia. Hemos podido identificar, entre 1929 y 1933, al menos diez expediciones frustradas, dirigidas, entre todas, a todos los grupos del Chaco boreal, al norte del río Pilcomayo ${ }^{13}$. De esa engorrosa lista, indudablemente incompleta, surge como denominador común la intención permanente de adentrarse en territorios indígenas lo más alejados posible del frente colonizador, generalmente en el Paraguay, y en todo caso siempre más allá del - para su gusto - demasiado aculturado Chaco argentino. Cada uno de estos planes fue frustrado por una desgraciada combinación del cada vez más tenso enfrentamiento entre Bolivia y Paraguay y, ante todo, la difícil situación política y financiera de su universidad. Más allá de sus breves cruces del Pilcomayo y una fugaz visita a los chamacoco en 1939, Métraux jamás consiguió realizar los estudios intensivos en el Chaco boreal con los cuales soñó durante muchos años.

13 Así pues, en su correspondencia, aquellas primeras impresiones optimistas iban a invertirse con una velocidad vertiginosa. Ya durante su primer viaje de 1929, Métraux comprendió que los recursos con los que contaba eran mucho más exiguos que lo previsto: debió recurrir a la ayuda de los franciscanos de Bolivia para financiar el final de su viaje ${ }^{14}$. Si a comienzos de ese año todavía conservaba una idea algo idílica de las capacidades financieras de su Universidad - y, por ejemplo, pretendía invitar a su costo a viejos colegas de Göteborg - este primer viaje le haría comprender con crudeza que su situación era mucho menos holgada. Por otro lado, la universidad de Tucumán entraba en una etapa conflictiva, signada por enfrentamientos políticos violentos y protestas estudiantiles, que no favorecieron la llegada de fondos para su instituto. En esta época enviaba una larga carta a Nordenskiöld llena de desaliento y pesimismo: "Tenía usted razón, un hombre honesto no puede venir a trabajar en este país. Anarquía, corrupción, bestialidad, mala fe, eso es todo lo que he encontrado aquí. No se me paga desde hace mucho tiempo, y por supuesto que el museo no tiene un centavo" (Tucumán, 15/10/1929, VM). En casi toda la correspondencia enviada desde Tucumán encontraremos expresiones similares, que van creciendo en exasperación. Abandonado por su familia, que debe regresar a Europa debido a una enfermedad del pequeño hijo, Métraux se describe « enterrado » en una ciudad de provincia: « He obligado a mi mujer, y luego a mi hijo, a compartir una vida mediocre y triste con el único objeto de algún día llegar a producir una obra útil. Consentí de buen grado venir a enterrarme en Tucumán, con la sola y única esperanza de poder realizar un trabajo original » (AM a PR, Tucumán, 
16/12/1929, MNHN, Ms. 1/6122). No renuncia, sin embargo, a los planes etnográficos más ambiciosos, y decide recurrir a cualquier ayuda que pueda conseguir para llevarlos a cabo. Por un lado, vende piezas a museos europeos: Berlín y Göteborg; por el otro, pide ayuda a sus amigos influyentes y trata de interesar a varios museos e instituciones de Estados Unidos - como el Field Museum y la Sociedad Geográfica de New York - en una gran expedición al Chaco boreal. En esas cartas, cada viaje proyectado es, a sus ojos, el último: "Si parto hacia el Isoso, pienso presentar mi renuncia », escribe apenas un año después de haber llegado a Tucumán (AM a EN, Tucumán, 01/12/1929, VM). Pero ninguno de estos proyectos prospera; Métraux se ve obligado a continuar vendiendo piezas para mantener vivo su Instituto, y tan sólo consigue realizar pequeñas expediciones arqueológicas a regiones cercanas. Comienza entonces a soñar con evasiones etnográficas más allá de Tucumán y el Chaco: ya en 1929 intentará formar parte de una expedición al Amazonas y Venezuela, en compañía de Nimuendajú (AM a EN, Tucumán, 15/10/1929, VM). Y al año siguiente sus planes de evasión irán mucho más lejos que la Amazonía; escribe a Nordenskiöld: "Busco un puesto en Australia [...]. En tal caso, abandonaré totalmente el americanismo. Lo lamento mucho, pero mala suerte. No puedo dedicar mi vida a esperar inútilmente la oportunidad de realizar una expedición» (Tucumán, 09/04/1930, VM). El maestro se muestra siempre dispuesto a ayudarlo: escribe las cartas de recomendación requeridas, compra sus colecciones y se ofrece como intermediario para otras ventas en Suecia. Por lo demás, parece compartir las peores opiniones de Métraux sobre el medio académico tucumano, aunque también le recuerda que sus sacrificios no serán en vano: « Es muy triste que sufra tantos problemas en Tucumán. Por otro lado, me alegra que tenga oportunidad de realizar investigaciones tan valiosas. Usted ya hizo, y seguirá haciendo, mucho por nuestra ciencia, y su gran conocimiento y su energía indomable un día volverán famoso su nombre » (EN a AM, Göteborg, 09/11/1929, VM, borrador).

14 En octubre de 1931, a pesar de su exitoso viaje a los chipaya, Métraux no sale del desasosiego; escribe a Nordenskiöld: "Tres años de absoluto aislamiento intelectual y moral en este rincón perdido de América me han agotado totalmente. [...] Pienso partir a Paraguay a comienzos de noviembre y quedarme cuatro o cinco meses con cualquier tribu indígena. La vida entre los indios es el único consuelo que encuentro en esta monotonía de mi existencia actual» (Tucumán, 24/09/1931, VM). Como sabemos, tampoco conseguirá realizar este viaje. En cambio irá a Suiza en diciembre, y a comienzos de 1932 pasará dos meses en Göteborg analizando sus materiales chipaya. Ignoramos cuáles fueron sus actividades en esa ciudad; lo cierto es que, al despedirse, una vez más el paso por Göteborg había obrado efectos rituales: « Vuelvo de allí con nuevas ideas, algunos trabajos en el cantero, y sobre todo con la convicción de que mis esfuerzos no son vanos » (AM a EN, Clarens, 01/04/1932, VM). Sería, aunque no podía saberlo, el último encuentro con su maestro, quien moría pocos meses más tarde.

A partir de la muerte de Nordensköld, Métraux reavivaría su vínculo con París y Paul Rivet - que había sido interrumpido por un entredicho epistolar. De hecho, su siguiente viaje al Chaco, pocos meses más tarde, sería «el primero realizado bajo el signo del Trocadéro » - que, en efecto, aportaría dinero para financiarlo (AM a PR, 27/04/1933, MNHN, Ms. 1/6132).

Esos dos viajes a la región del Pilcomayo argentino en 1933 iban a alterar drásticamente sus ideas tanto sobre el objeto de la etnografía como sobre el rol del etnógrafo. La intención inicial era viajar en compañía de la lingüista ruso-francesa Elisabeth Dijour al 
territorio nivaclé, al norte del estero Patiño, establecerse en una comunidad y practicar etnografía intensiva. Confinado al Chaco argentino por la guerra, encontraría un escenario mucho más desolador que en cualquiera de sus viajes anteriores: en todo el territorio pilagá la viruela había diezmado a los indígenas y los había forzado a dispersarse, y quienes sobrevivían debían enfrentar la violencia de los militares destacados en la región. Este escenario de violencia y miseria significó para Métraux el abandono, aunque momentáneo, de los ideales etnográficos de pureza cultural. Si sus escritos científicos anteriores manifestaban una notable resistencia a considerar los procesos de aculturación y cambio cultural, y procuraban restringir el análisis al rescate de objetos y relatos de un tipo cultural "puro » o "tradicional ", en los escritos que resultan de este viaje esos procesos y realidades híbridas serán descriptos, comentados y analizados. El resultado son, tal vez, las más ricas y complejas páginas chaqueñas que Métraux nos haya dejado, comenzando por sus Estudios de etnografía toba-pilagá (1937). Por otro lado, ante la desaparición física de los indígenas, el juicio ético se imponía sobre cualquier ideal científico: la etnografía de salvataje cultural debía ceder lugar al salvataje en sentido estricto. Es así que, durante este viaje, Métraux llegaría a abogar por procesos que, explícita y deliberadamente, se encaminaban hacia la aculturación. En primer lugar, gestionaría la instalación de una misión anglicana entre los pilagá de El Descanso: había aprendido de los propios indígenas que, en ese escenario, las misiones religiosas eran espacios de protección indispensables ${ }^{15}$. En segundo lugar, a mediados de 1933 se trasladó a Buenos Aires para realizar diversas gestiones ante el Estado argentino apoyando la creación de una colonia agrícola entre los toba-pilagá. El instituto estatal encargado de asuntos indígenas - la Comisión Honoraria de Reducciones de Indios - le ofreció entonces el cargo de Inspector General de los Indios del Chaco y Formosa, que en principio aceptó con entusiasmo. Escribía a Paul Rivet: «sería una cobardía negarme a una obra que podría ser útil a hombres. [...] El etnógrafo debe saber dejar su gabinete para lanzarse a la acción, sobre todo si ésta concierne a los hombres a cuyo estudio consagra la vida » (Tucumán, 29/05/1933, MNHN, Ms. 1/6133). Sin embargo, esta designación no llegaría a hacerse efectiva, y pocos meses más tarde Métraux regresaba a París, donde aceptaría la oferta de Rivet para integrar la expedición a la Isla de Pascua que lo alejaría para siempre de su puesto en Tucumán ${ }^{16}$.

\section{Regreso al Chaco (1939)}

17 Tal parecía ser el fin de sus investigaciones chaqueñas. $Y$, sin embargo, el Chaco no lo abandonaría. Por un lado, durante los años siguientes, en Honololú y Estados Unidos, continuó trabajando sobre sus materiales de campo y publicó algunos largos e importantes artículos sobre la región (Métraux 1937, 1939, 1943, 1946b). Aunque, a sus ojos, estas publicaciones fragmentarias no eran más que restos del naufragio del viejo proyecto: «Nunca hubiera pensado publicar estos cuentos y documentos si no tuviera buenas razones para creer que es poco probable que regrese al Chaco ", escribía en el prefacio de uno de estos trabajos (Métraux 1939, p. 1). Por el otro lado, el Chaco parecía hechizarlo más allá de cualquier escrito o plan concreto: en diversas cartas, entre 1935 y 1938, manifestaba la idea de regresar para culminar las investigaciones iniciadas una década antes. Así por ejemplo, escribía desde el barco que lo llevaba a Hawaii: « durante el día recuerdo todo lo que me falta hacer entre los indios del Chaco y mi buena conciencia helvética me reprocha el abandono de mi tarea, terminada a medias, y me acoge el deseo furioso de regresar » (AM a YO, 20/02/1935). Es así que desde Honololú 
impulsaría una expedición de Jules Henry al Chaco argentino, «donde se establecerá entre los toba y terminará la obra comenzada. [...] Los toba serán mucho mejor estudiados por él que lo que lo han sido por mí, y al final mi objetivo no sólo será alcanzado, sino que será sobrepasado" (AM a YO, Honololú, 03/04/1936). Pero este intento de delegación finalmente también fracasaría, y desde entonces Métraux comenzaría a planear su regreso con un atormentado entusiasmo: «En este momento suenan en la radio melodías argentinas: adiós Waikiki. Vuelvo a ver el Pilcomayo con sus aguas amarillas y esas espantosas caras de los oficiales argentinos. Dejar todo esto que me rodea por ese osario fétido. No puedes decir que me falta el sentido del deber » (AM a YO, Honololú, s./f., 1937).

Y, efectivamente, en 1939 estaba de regreso en el Chaco, financiado por la Fundación Guggenheim. Es interesante notar que, tanto en el plan de trabajo como en los informes posteriores enviados a Guggenheim, Métraux presentaba este viaje como una continuación del estudio integral del Chaco iniciado en Tucumán. Describía su expedición de 1933 como el inicio de un plan sistemático de cinco años de investigación, dividido en secciones temáticas, el cual se había visto accidentalmente interrumpido por la Guerra del Chaco. Aquella primera etapa, explicaba, había abordado la lingüística y el folklore - ya que los principales resultados del viaje de 1933 habían sido la compilación de vocabularios y el registro de mitos ${ }^{17}$. Su ordenado plan, así, proponía continuar durante otros cuatro años un estudio progresivo dirigido a completar una exhaustiva guía etnográfica del mundo chaqueño. En este proyecto hay otro punto de interés: el Chaco era presentado como área cultural discreta, exactamente en los mismos términos que luego sería abordado y clasificado por el Handbook of South American Indians. Intersección entre los Andes, las selvas y la Patagonia, el Chaco es - escribía - « una suerte de reserva de rasgos culturales antiguos» que ha recibido de esas tres áreas contiguas, y que por lo tanto contiene las claves para la «comprensión del pasado indígena » (cit. en Bilbao 2002, p. 85). En términos del Padre Cooper, una suerte de paradigma de las marginal tribes ${ }^{18}$.

19 Métraux se aprestaba a realizar, por fin, una etnografía intensiva: planeaba establecerse en una aldea wichí sobre el Pilcomayo, aprender la lengua, y comenzar por el estudio de la vida económica, la estructura social, y la etnobotánica. En cambio - como sabemos gracias a su Itinéraires... (Métraux 1978) - realizó un peregrinaje de algunos meses por el Chaco argentino y paraguayo y los Andes bolivianos. La situación era, una vez más, decepcionante: en la aldea wichí los indígenas habían adoptado el cristianismo y se mostraban renuentes a hablar sobre sus viejas costumbres. Se vio entonces obligado a estudiar problemas de organización social: la constitución de las unidades políticas, el parentesco, y fundamentalmente el problema de los frecuentes suicidios (Métraux 1943). No permaneció demasiado tiempo allí; en un informe enviado a Guggenheim explicaba: «Debo confesar que sufrí un gran desencanto. Durante los últimos diez años estos indios han sufrido grandes cambios. Ya no representan a la cultura chaqueña original como esperaba » (cit. en Bilbao 2002, p. 90). Decidió entonces intentar el proyecto tantas veces aplazado y cruzó el Pilcomayo hacia el Chaco paraguayo: primero entre los lengua, que también encontró decepcionantes; luego, remontando el río Paraguay, entre los chamacoco. Sin embargo, la situación aquí no era muy distinta: "encontré, lamentándolo mucho, que los antes orgullosos chamacoco habían sido reducidos a un manojo y que estaban completamente degenerados. No pensé que fuera aconsejable permanecer con ellos» (cit. en Bilbao 2002, p. 90). Regresó a Argentina para visitar las 
misiones anglicanas del río Bermejo; pero, por supuesto, tampoco aquí el cuadro se ajustaba a sus deseos. Al cabo de este viaje, escribía a Oddon: « No tengo más que malas noticias sobre mí. Como ves, he abandonado el Chaco argentino profundamente asqueado del estado en que encontré a los indígenas. [...] América del Sur se ha vuelto imposible, y lamento haber regresado. Pero, ay, ¿qué otra cosa podía hacer? » (Asunción, 29/05/1939).

Más allá del disperso - aunque fascinante - resultado de esa expedición, su proyecto para Guggenheim expresa con claridad dos rasgos centrales de su investigación chaqueña: en primer lugar, la urgencia por registrar los rasgos culturales considerados auténticos, o bien la búsqueda de los verdaderos indígenas, que parecían estar siempre más allá; en segundo lugar - como hemos visto -, el estudio de la región como un área cultural discreta. No es una casualidad, entonces, que las cartas de recomendación para su candidatura fueran escritas por dos responsables del Handbook, que entonces comenzaba a gestarse: John Cooper y Robert Lowie ${ }^{19}$. Y tampoco es casual que, al cabo de este último viaje, Métraux regresara a Estados Unidos para escribir un libro cuyo título proyectado era The Indians of the Gran Chaco, y que iba a transformarse en el largo capítulo chaqueño del Handbook - el cual continúa siendo una referencia insoslayable sobre la etnohistoria y etnografía de la región (Métraux 1946a).

\section{La sombra de Erland Nordenskiöld}

La pregunta sobre el origen de este persistente, obstinado - ciertamente " contra viento y marea »- interés por el Chaco remite sin dudas, al menos en parte, a la profunda y perdurable influencia de Erland Nordenskiöld. Métraux puede ser considerado el más importante de sus discípulos, y esto por diversos motivos. En primer lugar, sería toda su vida un fiel seguidor del acérrimo empirismo de Nordenskiöld, basado en dos reglas básicas: la preeminencia de los hechos por sobre cualquier teoría (en esta época, los grandes esquemas difusionistas), y el trabajo de campo como la fuente primaria de información. En una carta a Rivet, elevaba estos preceptos metodológicos al grado de máxima axiológica: «El programa de mi existencia se resume en un único deseo: la voluntad absoluta de encontrar algo nuevo y de salvar lo que se pueda salvar. He cumplido este programa en la medida de mis pobres, muy pobres medios, y tengo la convicción de que puedo estar conforme con mi tarea ${ }^{20}$.» Su principal preocupación fue siempre hacer lo que denominaba « obra original »: es decir, el registro de datos en el campo. En más de una carta de la época renegaba de la posibilidad de dedicarse a la etnología de gabinete -y, así, seguir los pasos de sus maestros franceses: «es difícil conjugar esa profesión de erudito con la de innovador e investigador de campo. Sólo esto cuenta. Los indios del Chaco están en una decadencia terrible. En 5 o 10 años no será casi posible estudiarlos con provecho » (AM a PR, Tucumán, 05/08/1929, MNHN, Ms. 1/6117). Métraux se alistaba de este modo, y sin medias tintas, en el linaje de Nordenskiöld, a quien « le gustaba hablar de la caducidad de su obra teórica, y se consolaba pensando que sus libros de viajes permanecerían como documentos sobre un mundo desaparecido ${ }^{21} »$ (Métraux 1932, p. 234).

Esta filiación fue cultivada activamente durante sus años en Tucumán. Apenas llegado a esa ciudad, escribía a Nordenskiöld: « ¡Quiero que Tucumán sea una sucursal de Göteborg en tierra americana! » (Tucumán, 02/01/1929, VM). Y pronto quedaba claro que esta intención era mucho más que una metáfora exaltada: expuso en su museo las fotos y mapas de distribución expuestos en Göteborg, mandó a fabricar vitrinas exactamente 
iguales a las suecas, e incluso procuró utilizar los mismos paños en los estantes ${ }^{22}$. Por otro lado, se esmeró por mantener un permanente intercambio de piezas etnográficas entre ambos museos. Al regreso de cada expedición o excavación, separaba para Nordenskiöld al menos algunas piezas especialmente seleccionadas, que a veces enviaba como donación, junto con cientos de fotografías ${ }^{23}$. Al menos en sus intenciones, entonces, Tucumán era realmente una sucursal de Göteborg, en la misma medida que él era ante todo un discípulo de Nordenskiöld: «Se lo he dicho a menudo y se lo repito: todas las colecciones privadas que yo posea, tarde o temprano, le llegarán » (Tucumán, 01/12/1929, VM). Al cabo de un año de generosas colaboraciones, el Museo de Göteborg le dedicaba una placa de bronce; la emocionada respuesta de Métraux es elocuente: « todo lo que pude hacer y quise hacer por su museo, fue únicamente por amistad y admiración hacia usted [...]. Su museo es el único por el cual siento un placer real de trabajar: [...] se asocia con los recuerdos de los años más fecundos y más agradables de mi existencia, y mientras viva haré lo posible por contribuir, en la medida de mis posibilidades, con su crecimiento ${ }^{24} »$.

Al enterarse de la muerte de su maestro, Métraux dirigió a su amiga y confidente Yvonne Oddon unas líneas que expresaban la profundidad de su afecto, y que vale la pena citar in extenso:

La noticia de la muerte de Nordenskiöld me ha sorprendido por una extraña coincidencia en mitad de mi viaje hacia el altiplano, en el mismo lugar donde hace treinta años Nordenskiöld comenzaba su carrera de hombre de ciencia. Durante toda la jornada desfilaron frente a mí las estaciones donde él hizo sus primeras excavaciones. El día estaba radiante, y en mitad de esos paisajes maravillosos de la Cordillera, casi no me era posible comprender que el único hombre de ciencia con quien me vinculé con todo mi corazón no existía más. Sin embargo, en cierto momento recordé la última noche que pasé en su casa, y tuve que esconderme para que no me vieran llorar. Es la primera vez que me siento así de conmovido por la desaparición de alguien. Mi cariño por Nordenskiöld era ante todo por su persona. Fue el único sabio a quien traté de cerca que estaba desprovisto de toda mezquindad. Lo que más apreciaba en él era su desdén por todas las formas de vanidad tonta, que los sabios no pueden evitar. Siempre me habló de ellas con ironía, y jamás buscó una gloria fácil. Amé también su generosidad, su desapego, su absoluta dedicación a la ciencia y a sus discípulos, y su espíritu irónico y alegre. Era verdaderamente un gran tipo. Creo haber sido su discípulo predilecto, y el último febrero volvió a decirme cuán feliz estaba de que yo continuara su obra y lo sucediera como americanista. ¿Para quién reuniré ahora colecciones? ¿De quién recibiré palabras de aliento? ¿Quién leerá y se interesará por mis trabajos? Me siento terriblemente desorientado, y mucho más solo. (Tucumán, 12/07/1932; ver Métraux 1932)

Volviendo a nuestra pregunta inicial, podemos sospechar que las obras chaqueñas de Nordenskiöld - y ante todo "La vida de los indios", el relato de su viaje al Chaco entre 1908 y 1909 - inspiraron a Métraux del mismo modo que las obras de Karl von den Steinen habían llevado a toda una generación de etnólogos hacia el Mato-Grosso y la Amazonía. Podemos suponer, sin demasiado riesgo, que su interés por el Chaco provenía, al menos en parte, de la admiración que profesaba por su maestro. Así lo sugiere la elección de los grupos étnicos que estudió - o planeó estudiar--, de las aldeas indígenas que visitó, y hasta de los problemas etnológicos que investigó - o proyectó investigar. Así, en su primer viaje a los chiriguanos en 1929, Métraux pasó por muchas de las aldeas visitadas por Nordenskiöld veinte años antes, e incluso indagó, registró y publicó el recuerdo que éste había dejado entre los indígenas (Métraux 1929c) ${ }^{25}$. De hecho, el proyecto original de este viaje, que no llegaría a completar por falta de recursos, incluía 
una visita a las aldeas chorote y nivaclé del Pilcomayo - es decir: planeaba repetir casi exactamente el itinerario seguido por Nordenskiöld en su viaje de 1908-1909. Y todo indica que con estos viajes se proponía llenar los vacíos y despejar los enigmas planteados por las investigaciones de su maestro. Así, la expedición a los chiriguano y chané de 1929 confirmaría las intuiciones de aquél sobre el doble origen de la cerámica de estos grupos; luego, a comienzos de 1930 planeaba investigar - en un viaje nunca realizado - dos zonas oscuras de la etnografía de Nordenskiöld: la «lengua secreta» de los isoseños y la presencia de esclavos ayoreo entre los tapietes; por último, a mediados de ese mismo año proyectaba estudiar el idioma de los nivaclé, quintaesencia del grupo chaqueño en los escritos del sueco.

Todo indica, entonces, que el Chaco descripto por Nordenskiöld formaba parte inseparable de los planes e impresiones etnográficas de Métraux, aunque más no fuera como término de contraste. Así, al cabo de su primer viaje describía de este modo los cambios ocurridos en la chiriguanía: « el momento no es tan favorable para este tipo de trabajo como lo era en su época. En este lapso, el Chaco se ha "civilizado" [...], y la Standard Oil hace surcar automóviles por la ruta que usted hizo a mula" (Cuevo, 09/03/1929, VM). Entre otras cosas, el Chaco era para Métraux el fascinante mundo indígena de los libros de su maestro, que veinte años de colonización estaban destruyendo, y que sus cambiantes itinerarios se empeñaban por recuperar.

En las décadas siguientes, a pesar de sus muchos desvíos por la Unesco, los Andes, Brasil, Haití, Polinesia o México, el Chaco continuaría siendo para Métraux el gran proyecto inconcluso al que tarde o temprano debía regresar. Pero, como sabe cualquiera que haya leído las páginas chaqueñas de Itinéraires (Métraux 1978, p. 55-110), el Chaco representaba para él, además de un ambicioso proyecto científico, el escenario de una búsqueda íntima y personal que no terminó, ni podía terminar, con la prodigiosa síntesis de información realizada en el Handbook. Una búsqueda que la famosa expresión "nostalgia del neolítico " parece iluminar, aunque tal vez no por las razones que él mismo invocara (Bing 1964). Su largo proyecto de investigación chaqueña, que se extendió desde su primera experiencia de campo hasta sus últimos planes de viaje, era en el fondo una tarea de Sísifo, inexorablemente incompleta, de la que huía y a la que regresaba, en parte porque consistía, precisamente, en la búsqueda obstinada de un mundo - personal y etnográfico al mismo tiempo - que sabía perdido. En 1940, al cabo de su último periplo chaqueño, luego de confesar a Yvonne Oddon que su viaje había sido un completo fracaso, que los indígenas lo habían decepcionado amargamente, y que ya nunca regresaría a la Argentina, escribía desde Yale:

\footnotetext{
Yvonne, ¿comprendes que estoy completamente solo y que el éxito que he podido tener lo he pagado destruyendo todo lo que hubiera podido traerme paz y felicidad? No me queda más que la etnografía. Estoy impaciente por regresar al Chaco únicamente para sentirme humano, para tener en mis brazos esos bebés morenos y curar a esos pobres tipos. Si tuviera alguna fe, seguramente me volvería misionero. Ojalá pudiera olvidarme y aprender a amar. (AM a YO, Yale, 15/12/1940)
}

Es así que en noviembre de 1962, en una carta que enviaba a la directora del Museo Etnográfico de Asunción para encomendarle a sus discípulos Pierre Clastres y Lucien Sebag, anunciaba: 
Tengo la esperanza de viajar al Paraguay el año próximo [...]. Me preparo para dejar la Unesco y retomar mi vida como etnógrafo. Como usted tal vez sepa, yo me había especializado en el Chaco, y querría continuar allí los trabajos que han quedado inconclusos. [...] Antes de elaborar un proyecto de estudio del Chaco, querría, por mí mismo, examinar el estado en que se encuentran los indios después de veinticinco años. (AM a BS, París, 13/11/1962, MEAB) fundación Wenner-Gren, y se inscribía cabalmente en el viejo proyecto: «Esta misión tendrá por objeto establecer un plan de investigaciones sistemáticas de un área cultural muy bien definida pero aún imperfectamente conocida ${ }^{26}$.» En otras palabras: volver a comenzar. Así, en la última carta que escribió a su gran amigo Pierre Verger, poco antes de quitarse la vida, Métraux reflexionaba: « pareciera que me veré forzado a recorrer el Chaco como hice hace 30 años. Es una forma de negar el paso del tiempo" (Le Bouler 1994, p. 307).

Ciertamente, al menos, una forma de nostalgia.

\section{BIBLIOGRAFÍA}

\section{AMENTA Sara Graciela (ed.)}

2008, Rodolfo Schreiter (1877-1942). Notas biográficas y epistolario de un naturalista, Fundación Miguel Lillo, Tucumán.

BERBERIAN Eduardo E. y Eugenia CAPIANO

1974, El Instituto de Antropología de la Universidad Nacional de Tucumán. Sus etapas y aportes a la cultura argentina, Ediciones Cabargon, Buenos Aires.

BILBAo Satiago A.

2002, Alfred Métraux en la Argentina. Infortunios de un antropólogo afortunado, Comala.com, Caracas.

BING Fernande

1964, « Entretiens avec Alfred Métraux », L’Homme, 4 (2), p. 20-32.

BOGGIANI Guido

1930, «Viajes de un artista por la América meridional. Los Caduveos: expedición al río Nabileque, en la región de las grandes cacerías de venados, Mato Grosso ", Revista del Instituto de Etnología,

1, p. 495-556.

BOSSERT Federico y Diego VILLAR

2007, « La etnografía chiriguano de Alfred Métraux », Journal de la société des américanistes, 93 (1), p. $127-166$.

CÓRDOBA Lorena

2015, « Etnógrafo-misionero, misionero-etnógrafo: Alfred Métraux y John Arnott », Boletín americanista, 55 (1), p. 95-112. 


\section{D'ANS André-Marcel}

1978, « Introduction », in Alfred Métraux, Itinéraires, 1. Carnets de notes et journaux de voyage (1935-1953), Payot, Paris, p. 9-22.

\section{KREBS Edgardo}

2007, « El escritor argentino y la tradición etnográfica », in Gonzalo Moisés Aguilar, Patricia Artundo y Edgardo Krebs, Oliverio Girondo. Exposición homenaje 1967-2007, Fundación Pan Klub/ Fundación Eduardo Constantini, Buenos Aires, p. 35-44.

\section{LAURIÈRE Christine}

2008, Paul Rivet. Le savant et le politique, Publications scientifiques du Muséum national d'histoire naturelle, Paris.

LE BOULER Jean-Pierre (ed.)

1994, Alfred Métraux. Pierre Verger. Le pied à l'étrier : correspondance, 1946-1963, Jean-Michel Place, Paris.

\section{MAUSS Marcel}

1969, «L'ethnographie en France et à l'étranger ", in Marcel Mauss, œuvres. 3. Cohésion sociale et divisions de la sociologie, Les Éditions de Minuit, Paris, p. 395-434.

\section{MÉTRAUX Alfred}

1925, « De la méthode dans les recherches ethnographiques », Revue d'ethnographie, 23-24, p. 266-290.

1927, « Le bâton de rythme. Contribution à l'étude de la distribution géographique des éléments de culture d'origine mélanésienne en Amérique du Sud », Journal de la société des américanistes, 19 (1), p. 117-122.

1928a, La civilisation matérielle des tribus Tupi-Guarani, P. Geuthner, Paris.

1928b, La Religion des Tupinambas et ses rapports avec celle des autres tribus Tupi-Guarani, Librairie Ernest Leroux, Paris.

1929a, « Deux anciens textes peu connus concernant l'institution du potlatch en Floride et dans le Chaco ", Journal de la société des américanistes, 21 (2), p. 417.

1929b, « Plan acerca de la creación de un museo etnográfico en Tucumán », Boletín de la Universidad Nacional de Tucumán, 35, p. 1-3.

1929c, « Le souvenir d'Erland Nordenskiöld dans le Chaco », Journal de la société des américanistes, 21 (2), p. 435-437.

1931, « Retour de M. A. Métraux », Journal de la société des américanistes, 23 (1), p. 265.

1932, « Introduction », Revista del Instituto de Etnología de la Universidad Nacional de Tucumán, 2 (2), p. 233-237.

1933, «A remarkable testimony and appeal from an Argentine scientist », South American missionary society, 66, p. 79-80.

1937, « Etudes d'ethnographie Toba-Pilaga (Gran Chaco) », Anthropos, 32, p. 171-194 y 378-401.

1939, « Myths and Tales of the Matako Indians (The Gran Chaco, Argentina) », Ethnological Studies, 9, p. 1-117.

1943, "Suicide among the Matako of the Argentine Gran Chaco », América Indígena, 3 (3), p. 199-209. 
1946a, « Ethnography of the Gran Chaco », in Julian H. Steward (ed.), Handbook of South American Indians, vol. 1, Smithsonian Institution, Washington, p. 197-370.

1946b, Myths of the Toba and Pilagá Indians of the Gran Chaco, American Folklore Society, Filadelfia.

1963, « Rencontre avec les ethnologues », Critique, 195-196, p. 677-684.

1978, Itinéraires, 1. Carnets de notes et journaux de voyage (1935-1953), Payot, Paris.

RIVET Paul

1933, « L'institut d'ethnologie de l'Université de Tucumán », Journal de la société des américanistes, 25 (1), p. 188-189.

RouGÉs Alberto

1999, Correspondencia (1905-1945), Fundación Miguel Lillo, Tucumán.

RYDÉN Stig

1936, Chaco. En resa bland fornlämnigar och indianer i argentinska och bolivianska Chaco,

Förlagsaktiebolaget Västra Sverige, Göteborg.

SOCIÉTÉ DES AMÉRICANISTES (SA)

1934, « Actes de la Société », Journal de la société des américanistes, 26 (1), p. 181.

WASSÉN Henry

1932, " Le musée ethnographique de Göteborg et l'œuvre d'Erland Nordenskiöld », Revista del

Instituto de Etnología de la Universidad Nacional de Tucumán, 2, p. 237-262.

\section{NOTAS}

1. Dado que esa correspondencia será citada profusamente, los nombres de los corresponsales serán reemplazados por sus iniciales: Robert Lehmann-Nitsche (RLN), Alfred Métraux (AM), Erland Nordenskiöld (EN), Yvonne Oddon (YO), Paul Rivet (PR), Stig Rydén (SR), Branislava Susnik (BS). El mismo sistema se utilizará para identificar los archivos y bibliotecas que la conservan: el Museo Etnográfico Andrés Barbero de Asunción (MEAB), el Ibero-Amerikanisches Institut de Berlín (IAI), la biblioteca del Muséum national d'Histoire naturelle de París (MNHN), el Laboratoire d'anthropologie sociale de París (LAS), el Collège de France (CF) y el archivo de los Världskulturmuseerna de Göteborg (VM). Agradezco calurosamente a diversas personas que, de diversas maneras, han colaborado con este breve escrito: Sophie Assal, Tamar Blickstein, Lorena Córdoba, Philippe Erikson, Mónica Ferraro, Jean-Pierre Goulard, Anne Gustavsson, Christine Laurière, Cecilia Martínez, Daniel Métraux, Solana Peña, Adelina Pusineri, Diego Villar, el personal del Centro Cultural Alberto Rougés y, muy particularmente, a Adriana Muñoz por recibirme en Göteborg y a Mickaël Brohan por poner a mi alcance parte de esta correspondencia. La investigación en los archivos de París fue realizada con el apoyo del proyecto PICS « Alfred Métraux: relecture transatlantique ».

2. EN a AM, s./f., 1927, VM, borrador. Antes de emprender este viaje hacia el norte argentino, Métraux escribía a Rivet que, ya que su proyecto inicial resultaba impracticable, realizaría breves viajes etnográficos: « Pienso también ir a Jujuy, y vivir algún tiempo en un "ingenio de azúcar" donde espero observar a los indígenas, sus costumbres, sus hábitos, y adquirir algunos objetos » (Mendoza, 29/05/1922, MNHN, Ms. 1/6111). En efecto, aquellos objetos enviados a Göteborg fueron coleccionados en Yacuiba, no lejos de la región de esos ingenios. 
3. Este artículo constituye una apología de los objetivos del Instituto de Etnología de París y muestra sensibles influencias de uno de sus directores, Lucien Lévy-Bruhl: «la humanidad "salvaje" aparece como un mundo cerrado, impermeable a nuestra experiencia, que permanece incomprensible si le atribuimos a quienes lo componen procesos mentales semejantes a los nuestros " (Métraux 1925, p. 277). Nociones que, en cierta medida, iban a teñir sus primeras quimeras etnográficas.

4. «El señor Métraux continúa trabajando asiduamente en su tesis, que espero interesará a sus maestros ", escribía Nórdenskiöld a Mauss (s./f., 1925, borrador) y, casi con las mismas palabras, a Rivet (Göteborg, 29/10/1925, MNHN, Ms. 1/6703).

5. Métraux anuncia este hallazgo en una carta de octubre de 1927 (AM a EN, París, 10/10/1927, VM). Aquí debemos corregir (e incluso invertir) la cronología esbozada por D’Ans (1978, p. 20), según la cual el grueso de la formación etnológica de Métraux tuvo lugar en Francia entre 1926 y 1927, y el viaje a Suecia recién se produjo en 1928. Por otro lado, la tesis doctoral (Métraux 1928a) responde cabalmente a los intereses y métodos micro-difusionistas que guían los Comparative Anthropological Studies de Nordenskiöld; y lo mismo cabe decir de algún artículo publicado en esos años (Métraux 1927).

6. Rivet no sólo era el principal etnólogo americanista francés, sino que también concentraba un poder sin precedentes en la política académica parisina; en él convergían las tres principales instituciones etnológicas: el Muséum, el Trocadéro y el Instituto de Etnología (Laurière 2008, p. 285, 370). Sus gestiones por Métraux en Tucumán se encuadraban en una estrategia más amplia: enviar etnógrafos franceses a diversos rincones del mundo, para que reunieran colecciones y convirtieran a París en un emporio etnológico (la misma razón que, en 1934, embarcaría a Métraux hacia la Isla de Pascua). No es casual, entonces, que Rivet presentara al Instituto de Etnología de Tucumán como una suerte de derivado del Instituto de Etnología de París (Rivet 1933).

7. Así, por ejemplo, escribía a Robert Lehmann-Nitsche « He encontrado aquí un medio inteligente, cultivado y desprovisto de todo prejuicio contra los extranjeros. El rector me apoya enteramente y estoy en excelentes condiciones para trabajar» (Tucumán, 29/12/1928, IAI; ver también AM a PR, Tucumán, 02/01/1929, MNHN, Ms. 1/6114).

8. Métraux transcribiría esos escuetos relatos en dos folios: « Mythes du Chaco, racontés par Vojtěch Frič lors de mon séjour a Prague » (LAS, FAM.AS.MT.02.01). En cuanto a los manuscritos - según confió a Nordenskiöld y Lehmann-Nistche -, Loukotka los había "tomado en préstamo " pues consideraba, como él mismo, un crimen permitir que acabaran « devorados por los ratones " (AM a EN, Lausanne, 12/09/1928, VM; AM a RLN, Lausanne, 15/08/1928, IAI). Ver también cartas a P. Rivet: Lausanne, 20/10/1928 y Tucumán, 15/10/1929 (MNHN, Ms. 1/6113 y Ms. 1/6119).

9. Antes de llegar a Argentina, Métraux ya había comenzado el estudio de las fuentes históricas chaqueñas; así, en un tomo de 1929 del Journal de la société des américanistes, publicaba una pequeña nota comparando el potlatch con una fiesta de los matará (1929a).

10. Métraux 1929b, p. 3. Ese grito de alarma de la etnología alemana había sido adoptado como una de las principales consignas del Instituto de Etnología de París y el Museo del Trocadéro, y proveía una buena razón para privilegiar la etnografía sobre la arqueología en Tucumán. En palabras del propio Marcel Mauss: «Esto debe hacerse sin demora. Los mismos hechos que debemos observar desaparecen cada día. Podemos esperar para excavar las ruinas o los monumentos prehistóricos, pero no podemos esperar para observar a pueblos todavía vivos, lenguas que pronto serán reemplazadas por mezclas, 
civilizaciones que cederán al contagio de nuestra uniforme cultura occidental» (Mauss 1969 [1913], p. 432; ver Laurière 2008, p. 358).

11. Carta de A. Rougés a AM, 1934 (Rougés 1999, p. 171). Así, por ejemplo, en 1935 el filósofo A. Rougés escribía al político E. Padilla que era necesario hallar el modo de traer de regreso a Métraux para que concluyera el proyecto chaqueño, piedra angular del Instituto de Etnología (Rougés 1999, p. 206).

12. SR a EN, 30/07/1932, VM. Rydén había llegado a Tucumán para realizar investigaciones arqueológicas y etnográficas bajo su supervisión. Luego de que se frustraran un viaje a los chipaya (por falta de fondos) y al Chaco paraguayo (por el inicio de la Guerra del Chaco), se instalaría en la estancia de un compatriota sueco en el Chaco boliviano, sobre el Pilcomayo. El avance de las tropas paraguayas lo forzaría a huir al cabo de tres semanas (ver Rydén 1936).

13. En marzo de 1929 a los chiriguano, chané, chorote, nivaclé, lengua y pilagá (AM a EN, Tucumán, 02/01/1929, VM); a fines de ese año al Chaco paraguayo (AM a PR, Tucumán, 16/12/1929, MNHN, Ms. 1/6122). En marzo de 1930 a la región del Isoso, para visitar a los tapiete y sus «esclavos" ayoreo (AM a EN, Tucumán, 01/12/1929, VM); en julio a los nivaclé (AM a EN, Tucumán, 20/02/1930, VM) y a los chiriguano del alto Pilcomayo (AM e EN, Tucumán, 09/04/1930, VM), en ambos casos para realizar estudios lingüísticos; en agosto nuevamente al alto Pilcomayo, esta vez para indagar las relaciones entre las culturas chicha y chiriguano (AM a EN, 22/05/1930). A fines de 1930, Rivet lo alienta a viajar al Paraguay; sin embargo, Métraux opta por realizar su viaje a la región chipaya (Bilbao 2002, p.42). En noviembre de 1931, un viaje a «cualquier grupo del Chaco paraguayo » (AM a EN, Tucumán, 24/09/1931, VM). Por fin, en 1932 se ve frustrado el viaje al Pilcomayo junto a Stig Rydén, para realizar « etnografía intensiva » entre los nivaclé.

14. « Mi viaje ha sido muy duro, y rico en aventuras desagradables. Todo por culpa de los "sinvergüenzas" de esta Universidad desgraciada, que luego de prometer enviarme el dinero, me dejaron absolutamente sin recursos. No sé cómo hubiera salido de este país del diablo si los misioneros franciscanos no me hubieran ayudado. Se me ha pasado cualquier deseo de hacer expediciones a cuenta de los criollos» (AM a EN, 15/10/1929, VM). Tal como los anglicanos iban a asistirlo en su segunda expedición de 1933: «tuve que andar cosa de 16 leguas por el monte llevando mis alforjas ni más ni menos como mula carguera. Por la más grande de las casualidades logré conseguir un matungo viejo y arrastrarme hasta la misión. [...] Esto siempre me pasa por andar pobre. ¡Cuándo podré hacer una expedición en forma debida!» (carta a R. Schreiter, Misión El Toba, 03/10/1933, en Amenta 2008, p. 223).

15. Al llegar a la región pilagá de El Descanso, Métraux fue recibido con algarabía por los hombres del cacique Lagadik: había sido confundido con un misionero anglicano, y pronto llegaron hombres de otras aldeas para ponerse bajo su protección. Dado que los pilagá hacían caso omiso a sus intentos por aclarar la confusión, y que « sabía bien que la fundación de una misión era el único medio para salvar a esta gente» (Métraux 1933), emprendió un viaje a la misión Sombrero Negro para gestionar esa fundación (al respecto, ver Córdoba 2015). Desde allí escribía a su amigo Rodolfo Schreiter: «Estoy instalado en una toldería donde desempeño casi a un tiempo las funciones de cacique y de médico. Vivo completamente solo entre la indiada gozando según Ud. ve de gran prestigio » (febrero de 1933, en Amenta 2008, p. 184).

16. Según surge de su correspondencia, Métraux llegó a recibir una - muy exiguacantidad de dinero para costear un viaje como inspector, que habría sido el que realizó 
entre agosto y diciembre de ese año. Sin embargo, por algún motivo que no resulta del todo claro, esa designación no llegaría a concretarse (AM a PR, Tucumán, 19/07/1933, MNHN, Ms. 1/6134B; AM a YO, Tucumán, 30/07/1933). A comienzos de 1934, de regreso en París, consiguió que la Société des américanistes realizara una declaración dirigida al presidente argentino, apoyando el plan de reorganización de las colonias indígenas propuesto por la Comisión Honoraria de Reducciones de Indios (SA 1934).

17. En efecto, buena parte de las libretas de campo conservadas en el legado Métraux del LAS consisten en vocabularios y registros - a veces bilingües - de mitos. Este aspecto de la etnografía de Métraux acusa una influencia directa de sus maestros franceses: las encuestas lingüísticas y la reunión de corpus mitológicos se contaban entre las principales actividades promovidas por el Instituto de Etnología, y por Rivet en particular (Laurière 2008, p. 239-240).

18. Por otro lado, una investigación exhaustiva y general del Chaco permitiría realizar reveladoras comparaciones con áreas culturales que, a su juicio, exhibían sugestivos paralelos - en particular, la región californiana.

19. Cooper destacaba allí « la importancia del Chaco como un área clave [...] por las implicaciones que tiene para la reconstrucción de la historia cultural panamericana » (cit. en Bilbao 2002, p. 249).

20. Tucumán, 16/12/1929, MNHN, itálicas mías. La elocuente expresión era repetida, casi como una fórmula ritual, un año más tarde: "Una sola cosa importa: ir al campo, acumular material y salvar todo lo que pueda salvarse. He hecho de esto una regla de vida, y toda mi energía está puesta en la realización de este objetivo " (AM a PR, Tucumán, 18/11/1930, MNHN, Ms. 1/6123).

21. Palabras que, al final de su vida, Métraux haría propias: «Creo que esta idea, realmente fundamental, ha inspirado mi carrera de etnógrafo: he querido conservar el recuerdo, o la imagen, de estas pequeñas civilizaciones [que] van a morir, sin dudas ya están muriendo » (Bing 1964, p. 23).

22. Un año y medio más tarde anunciaba triunfal: « Pienso inaugurar mi Museo en julio. Mi sala tendrá más o menos el aspecto de las del Museo de Göteborg, que tomé como modelo » (AM a EN, Tucumán, 22/05/1930, VM).

23. AM a EN, Tucumán, $1 / 12 / 1929$ y 16/8/1930, VM. Métraux ya gestionaba donaciones para Göteborg desde antes de viajar a Tucumán - a veces a costa de grandes esfuerzos, como en el caso de una gran balsa huarpe enviada desde Mendoza (AM a EN, París, 10/10/1927, VM).

24. AM a EN, Tucumán, 17/11/1930, VM. Por otro lado, Métraux realizó gestiones para que las obras de su maestro fueran publicadas en Francia (ofreciéndose, incluso, a realizar las traducciones), y, ante todo, publicó diversos artículos periodísticos, en Suecia y Argentina, exaltando el museo de Göteborg. Entre 1929 y 1932 planeó largamente un gran artículo sobre el tema: «Pienso publicar un estudio de Göteborg, con fotografías. Hace falta enseñar a esta gente lo que es un museo etnográfico " (AM a EN, Tucumán, 25/10/1929, VM). Finalmente sería encomendado a Henry Wassén y publicado en el tomo II de la Revista dirigida por Métraux (Wassén 1932).

25. En este escrito se percibe la satisfacción del alumno por registrar el afecto de los chiriguano hacia su maestro, y el orgullo porque éstos lo asociaran a él cuando le ofrecían los mismos objetos o le pedían el mismo precio por ellos. 
26. Carta de AM al Ministro de Educación Nacional de Francia, LAS, FAM.AS.C.03.19. La agenda, treinta años más tarde, seguía siendo una etnografía de salvataje: « confío poder salvar al menos la memoria de una de las más arcaicas culturas de Sudamérica " (carta de AM a Paul Féjos, París, 29/01/1963, LAS, FAM.AS.C.03.05). Como sabemos, Métraux nunca realizaría ese viaje. Sin embargo, algún tiempo después de su muerte, sus dos últimos discípulos iban a dejar las selvas guaraníes para dedicarse a estudios en el chaco boreal: Sebag entre los ayoreo, Clastres entre los nivaclé.

\section{RESÚMENES}

A través de una revisión de la correspondencia de Métraux con diversos interlocutores, se analiza el lugar central ocupado por el Gran Chaco en sus intereses etnológicos, y se identifica la persistencia de un proyecto de investigación que va desde el primer viaje de campo (1922) hasta su último proyecto etnográfico (1963). Se procura iluminar estos hechos reseñando el contexto biográfico de esas investigaciones y, en particular, enfatizando la importancia de su relación con el etnólogo sueco Erland Nordenskiöld.

L'examen de la correspondance de Métraux avec divers interlocuteurs révèle le rôle central que le Gran Chaco a joué dans ses intérêts ethnologiques et permet de mettre en évidence la persistance d'un projet de recherche qui va de la première expédition de terrain (1922) jusqu'à son dernier projet ethnographique (1963). L'article aborde le contexte biographique de ces recherches, en particulier l'importance de la relation entretenue par Métraux avec l'ethnologue suédois Erland Nordenskiöld.

This article analyzes the importance of the Gran Chaco to ethnologist Alfred Metraux by drawing on his personal letters and correspondence. In light of this biographical context, the article discusses the unrelenting place of the Chaco as an object of ethnological interest for Metraux from his first field trip (1922) to his final ethnographic project (1963), and explores the impact of his relationship with Swedish anthropologist Erland Nordenskiöld.

\section{ÍNDICE}

Keywords: Chaco, Alfred Métraux, Erland Nordenskiöld, history of anthropology

Palabras claves: Chaco, Alfred Métraux, Erland Nordenksiöld, historia de la antropología

Mots-clés: Chaco, Alfred Métraux, Erland Nordenksiöld, histoire de l'anthropologie

\section{AUTOR}

\section{FEDERICO BOSSERT}

Conicet, Universidad de Buenos Aires 